\title{
Comparison of Bond Properties Between ALWSCC and Steel Bars Based on Different Test Methods
}

\author{
Jianhui YANG ${ }^{\text {a, }}$, Wenchao ZHI ${ }^{\text {a }}$, Xujun TANG ${ }^{\mathrm{a}}$, Qinting $\mathrm{WANG}^{\mathrm{a}}$ and Tom \\ COSGROVE $^{\mathrm{a}, \mathrm{b}}$ \\ ${ }^{a}$ Henan Province Engineering Laboratory for Eco-architecture and the Built \\ Environment, Henan Polytechnic University, Jiaozuo, China \\ ${ }^{\mathrm{b}}$ Civil Engineering Department of Civil Engineering \& Materials Science, University \\ of Limerick, Dublin, Ireland
}

\begin{abstract}
Reasonable evaluation of the bond performance between steel bars and concrete has important theoretical and practical value for reinforced concrete structural design and seismic analysis. The stress $(\tau)-$ strain $(\varepsilon)$ formula is corrected based on a pull-out test, and the load $(F)$ - deflection $(w)$ curves are analyzed according to the change of stiffness before and after crack appearance based on a beam test, and new estimation formulas are given. At the same time, the bond properties are compared between all-lightweight shale ceramsite concrete (ALWSCC) and normal weight concrete (NWC). The results show that the bond property of ALWSCC is better than NWC. The bond stresses of pull-out specimens and beam specimens are the same or similar under equal conditions, but the ultimate load $\left(F_{0}\right)$ of the former is about 3.66 times that of the latter, the peak slip $\left(S_{0}\right)$ of the latter is 4.80 times that of the former, and the latter has significant splitting or pull-out failure characteristics. The peak slip $\left(S_{0}\right)$ in this paper is larger than that in the related literature, where the pull-out specimens are no more than 10 $\mathrm{mm}$, and are generally less than $2 \mathrm{~mm}$, while the beam specimens are not more than $3 \mathrm{~mm}$, with the others generally around $1 \mathrm{~mm}$. The research results have reference values and guiding significance for similar experimental research and engineering practice.
\end{abstract}

Keywords. All-lightweight concrete (ALWC), shale ceramsite, pull-out test, beam test, bond, deflection

\section{Introduction}

Because the linear expansion coefficients of reinforcement and concrete are similar, they have a good bonding effect, which is important to ensure that the structure can withstand various loads. Bond stress and bond slip are the characteristic parameters for evaluating whether steel bars and concrete can cooperate with each other. It is generally believed that the bond stress is mainly composed of three parts: chemical adhesive force, frictional resistance and mechanical bearing force [1]. The bond stress

\footnotetext{
${ }^{1}$ Jianhui Yang, Corresponding author, Henan Province Engineering Laboratory for Eco-architecture and the Built Environment, Henan Polytechnic University, Jiaozuo 454000, PR China; E-mail: yangjianhui@hpu.edu.cn.
} 
between a steel bar and concrete can be further divided into a bond stress at the end of the steel bar, and a bond stress among the cracks of the concrete, depending on the position of the bond stress. The bond stress between cracks is also called the local bond stress between the joints, and mainly occurs in the tension zone of the beam. Before the appearance of cracks, the chemical cementation force caused by the production of hydrated calcium silicate formed by the cement hydration reaction between the steel bar and the concrete is immersed in the surface of the steel bar. When the load of the beam reaches the cracking load, cracks will occur, and the concrete pulled between the joints will cause stress to act on the steel bars, resulting in a redistribution of the internal stress of the reinforced concrete [2-3]. The end bond of a steel bar mainly includes the end anchoring of the independent column, the anchoring of the beam end, the anchoring of the end of the cantilever beam, etc., and its function is to ensure synergy between the steel bar and the concrete. There must be a long enough anchoring length at both ends of the beam in order to obtain the corresponding anchoring force needed to bear the tensile stress of the steel in the beam, otherwise an anchoring failure problem will occur.

The most commonly used test methods for investigating the bond properties between concrete and steels are the direct pull-out test and the beam test. The direct pull-out test is divided into two types: cylindrical and cubic specimens according to the size of specimen. For example, Rolland et al. [4] used a cylinder of $\Phi 80 \mathrm{~mm} \times 200$ $\mathrm{mm}$ (diameter $\times$ height) with a bond length of $6 d$ (diameter of the bar), without stirrups; only a PVC tube sleeve with $(200-6 d) \mathrm{mm}$ was pre-buried at one end of the loading end, and the free end slip was measured with a non-contact laser displacement sensor. Patel et al. [5] used a cube of $200 \mathrm{~mm}$ side length, a bond section of $90 \mathrm{~mm}$ with stirrup constraints, a pre-buried length of $55 \mathrm{~mm}$ PVC sleeves at both ends, and a free end slip, using LVDT measurements. Pires Carvalho et al. [6] used a cylinder of $\Phi$ $80 \mathrm{~mm} \times 150 \mathrm{~mm}$ with a bond length of $100 \mathrm{~mm}$ without stirrups, and only a $50 \mathrm{~mm}$ length PVC tube casing embedded at one end of the loading end, and a cube with a side length of $200 \mathrm{~mm}$, having a bond length of $10 d$ without stirrups, and a PVC tube sleeve with $(200-10 d) \mathrm{mm}$ set at the loading end, where the free end slip was measured by LVDT. Bae et al. [7] used a cube with a side length of $150 \mathrm{~mm}$, a bond section of $3 d$ without stirrups, and a PVC sleeve with a length of $5 d$ at both ends, using LVDT for measuring the slip at the free end and the loading end. Similarly, Zhao et al. [8-11] introduced the corresponding pull-out test methods according to [12].

It can be seen from the test methods that the pull-out test is mainly used to study the end bond performance of the member, that is, the end portion of the beam and the anchoring point of the joint, and the overlapping portion of the continuous beam span. The failure modes can be divided into pull-out failure (POF), splitting failure (SF) and both of these [13]. During the test, the bond performance can be analyzed by measuring the stress-slip curve at the free end or the load end by LVDT, without consideration of the tension of the steel bars [14].

ACI-408R-03 [15] gives the beam test method, and GB 50010-2010 [16] introduces the reinforcement test method for a suitable beam. The methods used for beam tests are the anchorage beam test, the splice beam test and the beam-bending test. For example, Mousa [17] used a beam of $120 \mathrm{~mm} \times 200 \mathrm{~mm} \times 2250 \mathrm{~mm}$ (width $\times$ height $\times$ length) with a bond length of $1092 \mathrm{~mm}$, and a PVC tube of $504 \mathrm{~mm}$ length at both ends of the beam, and the beam deflection was measured by dial gages. Prince et al. [18] used a beam of $180 \mathrm{~mm} \times 225 \mathrm{~mm} \times 1700 \mathrm{~mm}$ with a splicing length of 400 $\mathrm{mm}$. The bottom splicing section is set with three LVDTs to measure the deflection. 
Dehestani et al. [19] used a beam with dimensions of $100 \mathrm{~mm} \times 150 \mathrm{~mm} \times 900 \mathrm{~mm}$ with a length of steel reinforcement at the bottom without a PVC sleeve. Pires Carvalho et al. [5] used a beam consisting of two half-beams of $100 \mathrm{~mm} \times 180 \mathrm{~mm} \times 800 \mathrm{~mm}$, with an anchorage length of $10 d$, where the PVC tube was used at the non-anchor section and two LVDT were set at the end of the reinforcement. The anchor beam test is a four-point bend with a specific anchor length and two curved cracks [20]. The splicing beam test uses a concrete beam with a known reinforced bond length and a known splicing length (the splicing length exists in the constant moment region) [2]. The whole beam test is to cast a complete beam according to the requirements of the specification, in which the length of the steel bar at the bottom is slightly longer than the beam [19]. The half-beam test consists of two symmetrical half-beams connected by a steel hinge at the top of the beam and a long steel bar at the bottom [21].

According to the above two kinds of bond-slip test methods, the pull-out specimen is simple and sensitive to the shape change of the steel bar, and the test data is easy to analyze, so it is commonly used as a benchmark for the study of bond performance [2223]. The beam specimen is larger and more complicated, and is thus used less in the literature, but it can directly reflect the bond anchoring performance of the steel bars under the bending moment and shear force, and the absolute value is much larger than the pull-out specimen because of the size effects [24-25].

Different type of concrete has different aggregates and mix ratios, which will thus affect the bond performance. For instance, Mo et al. [1], Zemour et al. [26], Al Shannag et al. [27] and others show that the bond behavior of lightweight aggregate concrete (LWAC) is much better than normal weight concrete (NWC), and in terms of structural use, it is more environmentally friendly, economical and technical. Because LWAC has obvious advantages in terms of light weight, good thermal performance, fire resistance and shock resistance, as well as environmental friendliness, it is widely used in the construction of high-rise buildings, long-span bridges and marine structures in harsh environments [28-29].

The term LWAC, or lightweight concrete (LWC) [30], is mainly determined by the name of LWAs, but because of the large variety of LWAs it is difficult to reflect the properties of LWAC. According to JGJ 51-2002 [31], concrete is called LWAC when its dry apparent density $\left(\rho_{\mathrm{d}}, \mathrm{kg} / \mathrm{m}^{3}\right)$ is no greater than $1950 \mathrm{~kg} / \mathrm{m}^{3}$; otherwise, it is named specified density concrete (SDC) when $1950 \mathrm{~kg} / \mathrm{m}^{3}<\rho d<2400 \mathrm{~kg} / \mathrm{m}^{3}$. On the other hand, if both fine and coarse aggregates are LWAs, the concrete is called alllightweight aggregate concrete (ALWAC) [32]. In order to enable LWAC to have the advantages of ALWAC and NWC, one method is to use a quantity of normal weight gravel to replace some of the lightweight coarse aggregate in equal volume, and the new concrete is called gravel lightweight concrete (GLWC), whose naming method refers to Taylor et al. [32].

Because the lightweight aggregates are shale ceramsite (SC) and shale pottery (SP) in this paper, the concrete is called all-lightweight shale ceramsite concrete (ALWSCC, hereinafter referred to as ALWC). The research objects are ALWC and GLWC, respectively, in this paper. It is precisely because the tube crushing strength (TCS, see table 1) of SC is generally lower than that of cement mortar that the strength formation mechanism of ALWC is different from NWC (mainly determined by the gravel). When the steel and concrete are destroyed under the same conditions, the SC will be destroyed by mortar first, so the bond strength is smaller, and the slip is larger, which is manifested as greater energy consumption when the steel bar is pulled out and destroyed. 
This paper aims to identify the differences and connections of the pull-out and beam test methods. A series of tests for bond-slip were carried out on several kinds of steel bars and ALWC and GLWC, in order to provide a basis for experimental and theoretical analysis for relevant research and applications.

\section{Experimental Program}

\subsection{Materials}

(1) Shale ceramsite (SC): gravel coarse aggregate, which must be pre-wetted $24 \mathrm{~h}$ ahead. The maximum particle size is $15 \mathrm{~mm}$. The bulk density is $660 \mathrm{~kg} / \mathrm{m}^{3}$. Water absorption is $10.9 \%$ at $24 \mathrm{~h}$. The tube crushing strength is $4.3 \mathrm{MPa}$.

(2) Shale pottery (SP): fine aggregate, with maximum size $5 \mathrm{~mm}$. The bulk density is $880 \mathrm{~kg} / \mathrm{m}^{3}$. Water absorption is $12.7 \%$ at $24 \mathrm{~h}$. The fineness modulus is 2.5 .

Both SC and SP were obtained from Luoyang Zhengquan Co., Ltd. (Luoyang, China), in line with Chinese national standard GB/T 17431.1-2010 [33]. Table 1 shows the sieving ratio, porous rate and tube crushing strength of SC and SP, respectively.

Table 1. The material parameters and experimental values for SC and SP.

\begin{tabular}{|c|c|c|c|c|c|c|}
\hline $\mathrm{SC}$ & $\begin{array}{l}>16 \mathrm{~mm} \\
(\%)\end{array}$ & $\begin{array}{l}16.0 \mathrm{~mm} \\
(\%)\end{array}$ & $\begin{array}{l}9.50 \mathrm{~mm} \\
(\%)\end{array}$ & $\begin{array}{l}4.75 \mathrm{~mm} \\
(\%)\end{array}$ & \multicolumn{2}{|c|}{ Porous rate $(\%)$} \\
\hline \multirow{3}{*}{$\begin{array}{l}\text { GB/T17431.1- } \\
2010 \text { [33] } \\
\text { experimental } \\
\text { values }\end{array}$} & $\leq 5$ & $\leq 10$ & $20-60$ & $85-100$ & $\mathrm{SC}$ & SP \\
\hline & 0.1 & 1.6 & 34.2 & 99.7 & 51.3 & 23.9 \\
\hline & \multicolumn{3}{|c|}{$\begin{array}{l}\text { Tube crushing strength (TCS) } \\
(\mathrm{MPa})\end{array}$} & Mean & $\begin{array}{l}\text { Over } \\
\text { mean }\end{array}$ & $\begin{array}{l}\text { GB/T17 } \\
431.1- \\
2010 \\
{[33]}\end{array}$ \\
\hline$\geq 9.50 \mathrm{~mm}$ & 3.63 & 3.67 & 3.68 & 3.66 & \multirow{2}{*}{3.62} & \multirow{2}{*}{$2.0-3.0$} \\
\hline$\geq 4.75 \mathrm{~mm}$ & 3.54 & 3.58 & 3.59 & 3.57 & & \\
\hline SP & $\begin{array}{l}4.75 \mathrm{~mm} \\
(\%)\end{array}$ & $\begin{array}{l}2.36 \mathrm{~mm} \\
(\%)\end{array}$ & $\begin{array}{l}1.18 \mathrm{~mm} \\
(\%)\end{array}$ & $\begin{array}{l}0.6 \mathrm{~mm} \\
(\%)\end{array}$ & $\begin{array}{l}0.3 \\
\mathrm{~mm}(\%)\end{array}$ & $\begin{array}{l}\leq 0.15 \\
\mathrm{~mm}(\%)\end{array}$ \\
\hline $\begin{array}{l}\text { GB/T17431.1- } \\
2010[33]\end{array}$ & $\leq 10$ & $\leq 35$ & $20-60$ & $30-80$ & $65-90$ & $75-100$ \\
\hline $\begin{array}{l}\text { experimental } \\
\text { values }\end{array}$ & 2.5 & 11.6 & 39.8 & 58.9 & 69.1 & 99.8 \\
\hline
\end{tabular}

Notes: The fineness modulus is 2.4-4.0 for this type SP in GB/T 17431.1-2010 [33].

(3) Gravel (G): The particle size is $5-20 \mathrm{~mm}$, the needle-like content is less than $10 \%$, and the bulk density is $1560 \mathrm{~kg} / \mathrm{m}^{3}$.

(4) Cement (C): PO 42.5 R Portland cement made at the Jiaozuo cement factory, brand Jiangu (Jiaozuo, China), which meets the Chinese national standard GB 1752007 [34].

(5) Fly ash (FA): grade II fly ash made at the Jiaozuo power plant (Jiaozuo, China), which meets the Chinese national standard GB/T 1596-2005 [35].

(6) Superplasticizer: Naphthalene series superplasticizer (FDN), meeting the Chinese national standard GB $8076-2008$ [36], whose water reducing ratio is $20 \%$, to which was added $1.8 \mathrm{wt} \% \%$ of cementitious materials. 
(7) Water: The running water met the Chinese national standard JGJ 63-2006 [37]. The reinforcements were used with CRB, which meets the Chinese national standard GB 1499.2-2007 [38]. Their mechanical parameters are shown in table 2.

Table 2. Strength for CRB.

\begin{tabular}{lll}
\hline$d(\mathrm{~mm})$ & $f_{\mathrm{y}}(\mathrm{MPa})$ & $f_{\mathrm{u}}(\mathrm{MPa})$ \\
\hline 12 & 460 & 580 \\
16 & 464 & 604 \\
20 & 422 & 572 \\
25 & 400 & 540 \\
\hline
\end{tabular}

\subsection{Pull-out Test}

The pull-out test method referred to GB/T 50152-2012 [39]. The specification size of the specimen was $150 \mathrm{~mm} \times 150 \mathrm{~mm} \times 150 \mathrm{~mm}$. The embedment length of steel bar $\left(l_{\mathrm{a}}\right)$ is $100 \mathrm{~mm}$ without transverse confinement. Polyvinyl chloride (PVC) tubes of length $25 \mathrm{~mm}$ were pre-embedded at two ends between the anchorage bar and concrete in order to avoid end-effects. The specified drawing of the pull-out specimen is shown in figure 1. Table 3 shows the test matrix used in the pull-out specimens of ALWC and GLWC (mixed according to the Chinese national standard of lightweight aggregate concrete JGJ 51-2002 [37] and normal weight concrete GB 50010-2010 [16], and the previous research results of our research group). All of the specimens were tested 28 days after casting.

The tests were carried out by a hydraulic pressure testing machine (made at the Changchun testing machine factory, China) with a maximum load capacity of $1000 \mathrm{kN}$, and the loading rate was $6 \mathrm{kN} / \mathrm{min}$. The specimen was regarded as a failure and the loading stopped when splitting failure (SF) or pull-out failure (POF) occurred, if the aggregates in a fracture plane were crushed in the shape of a soil body turned by a plow (called scrapping-type failure), or if the total slip $S=25 \mathrm{~mm}$.

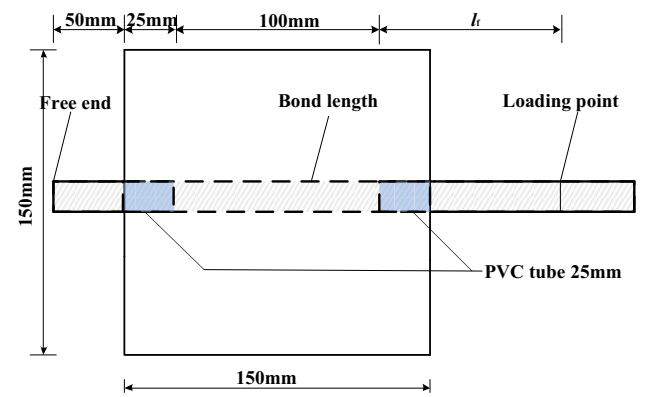

Figure 1. Schematic drawing for cube specimen. (Notes: For the ALWC, $l_{\mathrm{f}}=140 \mathrm{~mm}$, for the GLWC, $l_{\mathrm{f}}=$ $80 \mathrm{~mm}$.

Table 3. Mixes $\left(1 \mathrm{~m}^{3}\right)$ and technical parameters for pull-out specimens (A) and beam specimens (B).

\begin{tabular}{lllllllllllll}
\hline $\begin{array}{l}\text { Test } \\
\text { No. }\end{array}$ & Type & $\begin{array}{l}m_{\mathrm{C}} \\
(\mathrm{kg})\end{array}$ & $\begin{array}{l}m_{\mathrm{FA}} \\
(\mathrm{kg})\end{array}$ & $\begin{array}{l}m_{\mathrm{SC}} \\
(\mathrm{kg})\end{array}$ & $\begin{array}{l}m_{\mathrm{SP}} \\
(\mathrm{kg})\end{array}$ & $\begin{array}{l}m_{\mathrm{G}} \\
(\mathrm{kg})\end{array}$ & $\begin{array}{l}m_{\mathrm{W}} \\
(\mathrm{kg})\end{array}$ & $\begin{array}{l}f_{\mathrm{cu}} \\
(\mathrm{MPa})\end{array}$ & $S D_{\mathrm{cu}}$ & $\begin{array}{l}f_{\mathrm{ts}} \\
(\mathrm{MPa})\end{array}$ & $S D_{\mathrm{ts}}$ & $\begin{array}{l}\rho_{\mathrm{d}} \\
\left(\mathrm{kg} / \mathrm{m}^{3}\right)\end{array}$ \\
\hline $\mathrm{A}_{1}$ & $\mathrm{ALWC}$ & 479 & 202 & 387 & 446 & - & 259 & 31 & 2.08 & 2.59 & 0.18 & 1712 \\
$\mathrm{~A}_{2}$ & GLWC & 481 & 157 & 311 & 408 & 339 & 172 & 32 & 2.08 & 3.11 & 0.13 & 1792 \\
\hline
\end{tabular}




\begin{tabular}{lllllllllllll}
\hline $\mathrm{B}_{1}$ & ALWC & 436 & 152 & 475 & 370 & - & 200 & 31 & 1.73 & 1.88 & 0.08 & 1752 \\
$\mathrm{~B}_{2}$ & ALWC & 467 & 155 & 460 & 385 & - & 205 & 36 & 1.00 & 2.14 & 0.12 & 1780 \\
$\mathrm{~B}_{3}$ & ALWC & 495 & 159 & 444 & 408 & - & 209 & 38 & 0.58 & 1.91 & 0.04 & 1732 \\
\hline
\end{tabular}

Notes: $m_{\mathrm{C}}$ is the mass of cement. $m_{\mathrm{FA}}$ is the mass of fly ash. $m_{\mathrm{SC}}$ is the mass of shale ceramsite. $m_{\mathrm{SP}}$ is the mass of shale pottery. $m_{\mathrm{W}}$ is the mass of water. $f_{\mathrm{cu}}, f_{\mathrm{ts}}$ are the arithmetic mean of cubic $(150 \mathrm{~mm} \times 150 \mathrm{~mm} \times$ $150 \mathrm{~mm}$, three specimens) compressive strength at $28 \mathrm{~d}$, and splitting tensile strength, respectively. $S D_{\text {cu }}, S D_{\text {ts }}$ are the standard deviation (SD) of three cubic compressive strengths and three splitting tensile strengths, respectively. $\rho_{\mathrm{d}}$ is the dry apparent density at $28 \mathrm{~d}$. The slump is $165-190 \mathrm{~mm}$.

\subsection{Beam Test}

The dimensions of beam specimens are $150 \mathrm{~mm} \times 240 \mathrm{~mm} \times 1270 \mathrm{~mm}$, and three specimens named $\mathrm{B}_{1}, \mathrm{~B}_{2}, \mathrm{~B}_{3}$, respectively were made. The $\mathrm{B}_{1}$ beam bottom bar diameter is $25 \mathrm{~mm}$, and the concrete cover layer thickness is $50 \mathrm{~mm}$. The $\mathrm{B}_{2}$ beam bottom bar diameter is $20 \mathrm{~mm}$, and the concrete cover layer thickness is $40 \mathrm{~mm}$. The $\mathrm{B}_{3}$ beam bottom bar diameter is $16 \mathrm{~mm}$, and the concrete cover layer thickness is $30 \mathrm{~mm}$. The bundled steel cage was put into the prepared wooden formwork, and then the two half-beams were connected through the embedded steel hinge (figure 2c), which is 70 $\mathrm{mm}$. The long steel bar passes through the central axis of the width of the bottom section of the two half-beams, and extends $50 \mathrm{~mm}$ at each end, and is used to measure the slip length. The design of the reinforcement in the beam is shown in table 4.

Figure 2 shows the beam specimen and the position of the strain gages: the strain gage spacing of the $\Phi 16 \mathrm{~mm}$ steel is $53.3 \mathrm{~mm}$, of the $\Phi 20 \mathrm{~mm}$ steel is $66.6 \mathrm{~mm}$, and of the $\Phi 25 \mathrm{~mm}$ is $83.3 \mathrm{~mm}$. Table 4 shows the test matrix used in the beam specimens of ALWC.

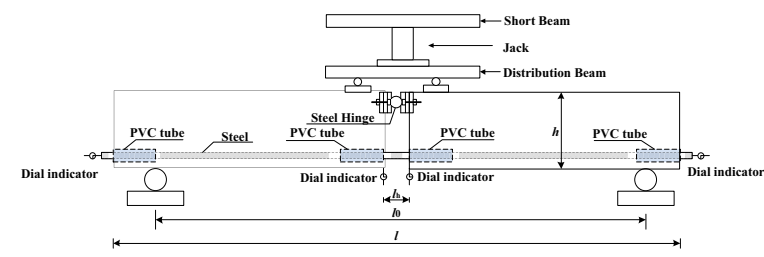

(a) Details of the beam specimen

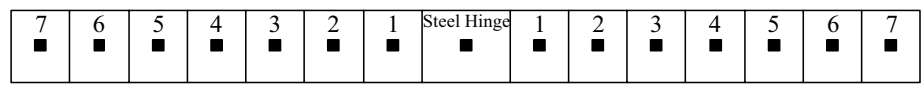

(b) Location of steel strain gages for beam test

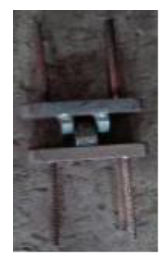

(c) Photo of steel hinge

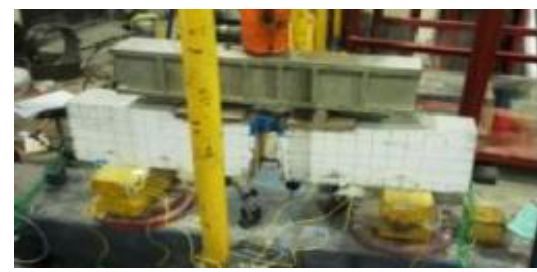

(d) Photo of field test

Figure 2. Schematic drawing and photos for beam specimen. 
Table 4. Beam specimen reinforcement table ( $\mathrm{mm})$.

\begin{tabular}{|c|c|c|c|c|c|c|c|}
\hline & $\begin{array}{l}\text { Schematic } \\
\text { diagram }\end{array}$ & Type & $\begin{array}{c}\text { Diameter } \\
(d)\end{array}$ & $f_{\mathrm{y}}(\mathrm{MPa})$ & $f_{\mathrm{u}}(\mathrm{MPa})$ & Dimensions & Number \\
\hline $\begin{array}{l}\text { Upper } \\
\text { ribs }\end{array}$ & & PSB & 12 & 240 & 373 & 560 & 24 \\
\hline $\begin{array}{l}\text { Bottom } \\
\text { ribs }\end{array}$ & & PSB & 12 & 240 & 373 & 560 & 24 \\
\hline $\begin{array}{l}\text { Stirrup } \\
1\end{array}$ & & PSB & 8 & 233 & 368 & $110 \times 200$ & 60 \\
\hline $\begin{array}{l}\text { Stirrup } \\
2\end{array}$ & & PSB & 8 & 233 & 368 & $160 \times 280$ & 60 \\
\hline $\begin{array}{l}\text { Longer } \\
\text { ribs }\end{array}$ & & CRB & $\begin{array}{l}16 \\
20 \\
25\end{array}$ & $\begin{array}{l}405 \\
426 \\
440\end{array}$ & $\begin{array}{l}567 \\
572 \\
580\end{array}$ & $\begin{array}{l}1350 \\
1350 \\
1350\end{array}$ & $\begin{array}{l}2 \\
2 \\
2\end{array}$ \\
\hline
\end{tabular}

Loading was applied with a universal machine through a reaction frame and a QYL type jack controlled by a microcomputer and loaded in a force control mode with a step size of $5 \mathrm{kN} /$ grade. The data was recorded by the 1211832 static resistance strain gage and at the same time two dial indicators were placed respectively at the free end of the steel bars to measure the slip while another two were placed at the two sides of the middle of the half-beam to record deflection.

\section{Experimental Results and Discussion}

\subsection{Pull-Out Tests}

\subsubsection{Test Curve Analysis.}

The bond stress calculation formula is shown in equation (1).

$$
\tau=P\left(\pi d l_{\mathrm{a}}\right)^{-1}
$$

where $\tau$ is the average bond stress (MPa), $P$ is the pull-out load $(\mathrm{kN}), d$ is the diameter of reinforcement $(\mathrm{mm})$, and $l_{\mathrm{a}}$ is the anchorage length $(\mathrm{mm})$.

Before the test, the force and displacement sensors of the machine were calibrated, and the hanging basket of the fixed sample was monitored during the test. No horizontal and vertical displacement was produced by the hanging basket, which confirms that it is feasible to test by this method. Considering the tensile behavior of the non-bonded section of the steel bar under loading, the modified formula for calculating the average bond stress according to Hook's laws is shown in equation (2), and equation (3) presents the conversion relationship between the actual slip and the slip given by the microcomputer.

$$
\begin{aligned}
& \Delta l=\left(P l_{\mathrm{f}}\right)\left(E_{\mathrm{s}} A\right)^{-1} \\
& S=S_{\mathrm{DS}}-\Delta l
\end{aligned}
$$


where $\Delta l$ is the elongation of the loading point of the steel bar to the bond point $(\mathrm{mm})$, $l_{\mathrm{f}}$ is the distance of the loading point of the steel bar to the bond point (mm), $E_{\mathrm{s}}$ is the reinforcement modulus (GPa), $A$ is the reinforced section area $\left(\mathrm{mm}^{2}\right), S$ is the slip $(\mathrm{mm})$, and $S_{\mathrm{DS}}$ is the slip directly measured by the displacement sensor of the test machine $(\mathrm{mm})$.

According to equation (1), equation (2), and equation (3), the $P$ - $S$ curves obtained directly from the computer are converted into a corresponding $\tau-S$ curve. This is shown in figure 3.

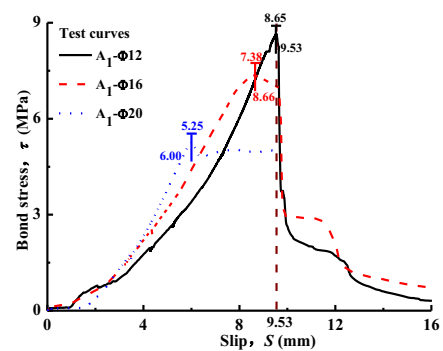

(a) ALWC

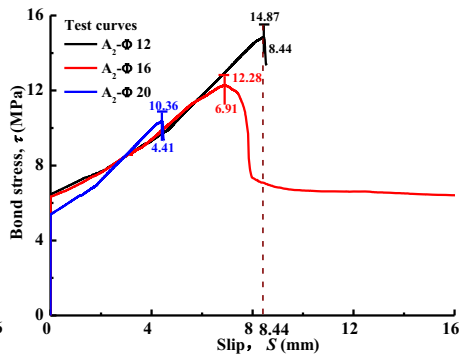

(b) GLWC

Figure 3. Curves of $\tau-S$ for pull-out specimens.

From the analysis of the curve and the test phenomena, it is found that the curves of specimens in which pull-out damage decreased rapidly after the peak stress, and the test curves have complete ascending and descending segments. The specimen with cracking damage will make a loud "bang", and will then be destroyed and split into 2 or 3 pieces.

It can be clearly observed that the bond stress of GLWC is greater than that of ALWC, which is because of the lower tube crushing strength of ceramsite. When the damage occurs, the SC is destroyed first. But because of the gravel in GLWC, the bond stress is improved.

Comparing the test phenomena of different groups, it can be seen that specimens with a large diameter are more prone to splitting damage, and the ultimate bond stress decreases with increasing diameter, while the limit slip is gradually decreasing. In the ALWC, the ultimate bond stress $\left(\tau_{0}\right)$ of the specimen with $16 \mathrm{~mm}$ diameter was reduced by $14.68 \%$ compared with the specimen with $12 \mathrm{~mm}$ diameter. The specimen with 20 mm diameter was reduced by $39.31 \%$. In the GLWC, the $\tau_{0}$ of the specimen with 16 $\mathrm{mm}$ diameter was reduced by $17.42 \%$; the specimen with $20 \mathrm{~mm}$ diameter was reduced by $30.33 \%$.

The failure models of specimens are shown in figure 4 .

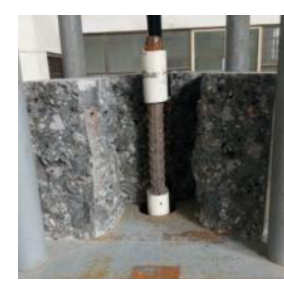

(a) Pull-out failure.

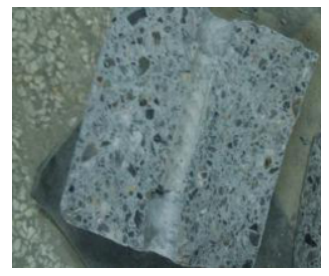

(b) Splitting failure.

Figure 4. Failure modes for pull-out specimens. 


\subsubsection{Comparative Analysis of Ultimate Bond Stress and Corresponding Slip}

Table 5 summarizes the different types of concrete bond properties. All the specimens were cubes with dimensions $150 \mathrm{~mm} \times 150 \mathrm{~mm} \times 150 \mathrm{~mm}$. Figure 5 shows the scatter plots of the ultimate bond stress and corresponding slip.

Table 5. Parameters of bond-slip in this paper and the literatures based on cubic pull-out specimens.

\begin{tabular}{|c|c|c|c|c|c|c|}
\hline & $f_{\text {cu }}(\mathrm{MPa})$ & $\tau_{0}(\mathrm{MPa})$ & $S_{0}(\mathrm{~mm})$ & $d(\mathrm{~mm})$ & $l_{\mathrm{a}}(\mathrm{mm})$ & FM \\
\hline \multicolumn{7}{|l|}{ This paper } \\
\hline \multirow{3}{*}{ ALWC } & 28 & 8.65 & 9.53 & 12 & 100 & POF \\
\hline & 31 & 7.38 & 8.66 & 16 & 100 & POF \\
\hline & 33 & 5.25 & 6.00 & 20 & 100 & $\mathrm{SF}$ \\
\hline \multirow{3}{*}{ GLWC } & 32 & 14.87 & 8.44 & 12 & 100 & $\mathrm{SF}$ \\
\hline & 32 & 12.28 & 6.91 & 16 & 100 & $\mathrm{POF}$ \\
\hline & 35 & 10.36 & 4.41 & 20 & 100 & $\mathrm{SF}$ \\
\hline \multicolumn{7}{|c|}{ Expanded shale concrete (ESC) } \\
\hline \multirow{3}{*}{$\begin{array}{l}\text { Wu et al. } \\
(2013) \text { [40] }\end{array}$} & 40 & 18.50 & 1.03 & 12 & 60 & POF \\
\hline & 35 & 15.30 & 0.77 & 16 & 80 & SF \\
\hline & 45 & 11.70 & 0.10 & 22 & 110 & $\mathrm{SF}$ \\
\hline \multicolumn{7}{|c|}{ Ceramsite Concrete (CC) } \\
\hline \multirow{3}{*}{$\begin{array}{l}\text { Zhang and } \\
\text { Yang (2014) } \\
{[41]}\end{array}$} & 21 & 12.10 & 0.55 & 16 & 80 & POF \\
\hline & 30 & 18.20 & 0.79 & 16 & 60 & $\mathrm{SF}$ \\
\hline & 29 & 14.10 & 0.83 & 16 & 100 & $\mathrm{SF}$ \\
\hline \multicolumn{7}{|c|}{ Structural lightweight concrete (SLC) } \\
\hline \multirow{6}{*}{$\begin{array}{l}\text { Al-Shannag } \\
\text { and Charif } \\
(2017)[27]\end{array}$} & 34 & 6.70 & 1.51 & 12 & 150 & $\mathrm{SF}$ \\
\hline & 34 & 4.29 & 1.48 & 16 & 150 & $\mathrm{SF}$ \\
\hline & 34 & 3.13 & 1.22 & 20 & 150 & $\mathrm{SF}$ \\
\hline & 48 & 8.47 & 1.61 & 12 & 150 & SF \\
\hline & 48 & 6.71 & 1.75 & 16 & 150 & $\mathrm{SF}$ \\
\hline & 48 & 5.23 & 1.26 & 20 & 150 & $\mathrm{SF}$ \\
\hline \multicolumn{7}{|c|}{ Normal weight concrete (NWC) } \\
\hline \multirow{3}{*}{$\begin{array}{l}\text { Pires } \\
\text { Carvalho et } \\
\text { al. }(2018)[6]\end{array}$} & 35 & 12.10 & 0.90 & 6 & 63 & $\mathrm{SF}$ \\
\hline & 35 & 7.20 & 1.01 & 8 & 80 & SF \\
\hline & 35 & 9.00 & 1.00 & 10 & 100 & $\mathrm{SF}$ \\
\hline
\end{tabular}

Notes: $\tau_{0}$ is the peak bond strength, $S_{0}$ is the slip corresponding to $\tau_{0}$, FM means the failure models, POF means pull-out failure, SF means splitting failure.

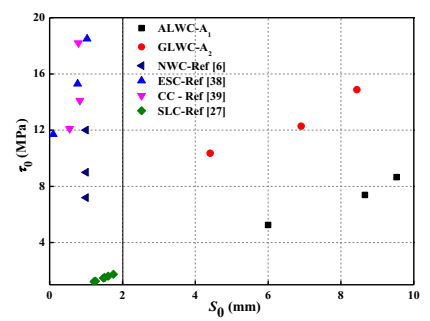

Figure 5. Scatter plot of $\tau_{0}$ versus $S_{0}$ for pull-out specimens. 
Comparing table 5 and figure 5 , it can be seen that even if the matrix materials are similar, the differences in $\tau_{0}-S_{0}$ obtained by different works in the literature are also large. For example, the bond stress of structural lightweight concrete with the highest compressive strength studied by Al-Shannag and Charif [27] is significantly lower. The compressive strength of shale ceramsite lightweight concrete for this research is generally lower than that of natural lightweight aggregate concrete, but its bond strength is obviously higher than others. The $S_{0}$ of shale ceramsite lightweight aggregate concrete exceeds $2 \mathrm{~mm}$, and the average value is $1.47 \mathrm{~mm}$, which is significantly higher than the rest of the concrete (not more than $2 \mathrm{~mm}$ ). This may be due to the lower modulus of elasticity and greater total deformation of shale ceramsite lightweight aggregate concrete (see table 6).

Table 6. Elastic modulus of ALWC and NWC.

\begin{tabular}{lllll}
\hline ALWC / NWC & LC25 / C25 & LC30 / C30 & LC35 / C35 & LC40 / C40 \\
\hline$E\left(\times 10^{4} \mathrm{MPa}\right)$ & $1.36 / 2.80$ & $1.51 / 3.00$ & $1.65 / 3.15$ & $1.80 / 3.25$ \\
$E_{\mathrm{LC}} / E_{\mathrm{C}}(\%)$ & 48.57 & 50.33 & 52.38 & 55.38 \\
\hline
\end{tabular}

Notes: The elastic modulus of NWC and ALWC is from GB 50010-2010 [18], and tested by this paper, respectively.

The elastic modulus of ALWC is generally about $50 \%$ of the same grade NWC (see table 6), and its total strain $(5500 \mu \varepsilon)$ is about 2 times that. According to the energy consumption analysis, ALWC has greater resistance to deformation and has higher energy consumption; that is, the slip value is much larger than that of the NWC.

\subsection{Beam Tests}

\subsubsection{The Physical-Mechanical Model}

According to the force mechanism of the beam, the half-beam is selected for calculation and analysis as shown in figure 6.

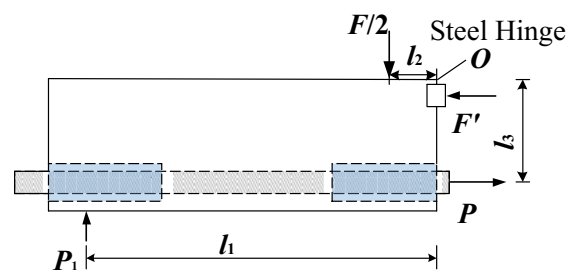

Figure 6. Sketch for half-beam analysis.

Figure 6a shows that the loading mode is a local uniform load. Therefore, it should be converted into a concentrated load and then converted to the tensile force at the bottom of the beam using equation (4).

$$
\sum M_{O}=P_{1} l_{1}-F l_{3}-\frac{P l_{2}}{2}=0
$$

where $\sum M_{O}$ is the moment of point $O(\mathrm{kN} \cdot \mathrm{mm}), P$ is the horizontal pull force $(\mathrm{kN}), P_{1}$ is the force of support reaction $(\mathrm{kN}), F / 2$ is the force transformed by the local uniform 
loads $(\mathrm{kN}), l_{1}$ is the horizontal distance between the center of the support and the point $O(465 \mathrm{~mm}), l_{2}$ is the horizontal distance between the point of $F / 2$ and the point $O(100$ $\mathrm{mm})$, and $l_{3}$ is the vertical distance between the center of the bars and the point $O(\mathrm{~mm})$.

During the test, the bottom of the beam will inevitably produce a certain degree of deflection, and the beam end will inevitably produce a certain angle of rotation. In order to eliminate the effects of deflection and rotation angle, the force of the bottom steel bar is decomposed to obtain the component force in the horizontal direction, which is the true pull-out force. At the same time, the strain measured by the strain gages is affected by the influence of the additional bending strain generated by the bending moment. According to the relationship between the deflection and rotation angle, the strain measured by the test is converted as follows:

$$
\begin{aligned}
& w^{\prime \prime}=-\frac{M(x)}{E_{\mathrm{LC}} I} \\
& w^{\prime}=-\int \frac{M(x)}{E_{\mathrm{LC}} I} \mathrm{~d} x+C=\tan \theta \\
& \varepsilon=\varepsilon_{x} \cdot \cos \theta
\end{aligned}
$$

where $w$ is the deflection ( $\mathrm{mm}), M(x)$ is moment equation, $x$ is the horizontal distance from point $O$ to any point $(\mathrm{mm}), E_{\mathrm{LC}}$ is the elastic modulus of LWAC $(\mathrm{GPa}), I$ is the section moment of inertia $\left(\mathrm{mm}^{4}\right), C$ is the integral constant, $\theta$ is the angle, $\varepsilon$ is the horizontal strain value $\left(10^{-6}\right)$, and $\varepsilon_{x}$ is the actually measured strain value $\left(10^{-6}\right)$.

\subsubsection{Analysis of the $\tau-\varepsilon$ Curves}

The $\tau-\varepsilon$ curves of the steel bar at the bottom are converted through the above transformation, and the $\tau-\varepsilon$ relationship in the horizontal direction is shown in figure 11. The crack distribution at the bottom of the beam is shown in figure 7 .

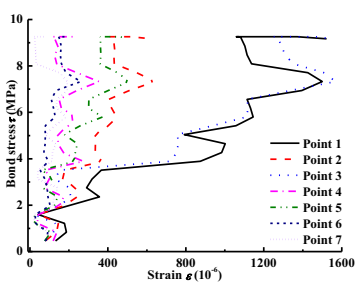

$\left(\mathrm{a}_{1}\right) \mathrm{B}_{1}, \mathrm{LC} 30$

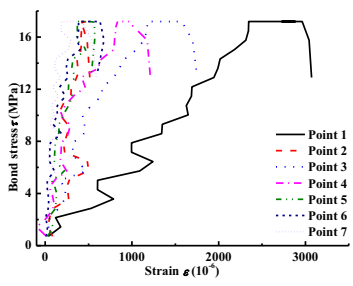

$\left(\mathrm{a}_{2}\right) \mathrm{B}_{2}, \mathrm{LC} 35$

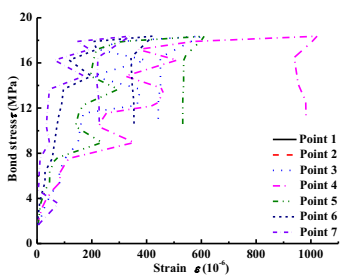

$\left(\mathrm{a}_{3}\right) \mathrm{B}_{3}, \mathrm{LC} 40$

Figure 7. Curves of $\tau-\varepsilon$ in horizontal direction of beam specimens. 


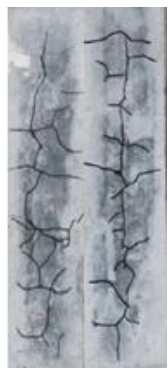

$\left(b_{1}\right) B_{1}$

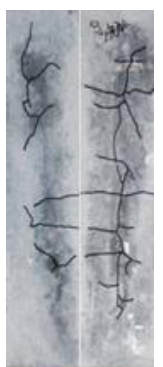

(b) $\mathrm{B}_{2}$

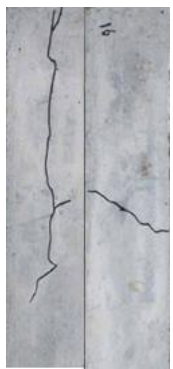

(b) $\mathrm{B}_{3}$

Figure 8. Photos of cracks on beam bottom.

Comparing figure 6, figure 7 and figure 8 , it can be seen that the value of Point 1 (the beam span, where the crack first appears and the crack is the longest) is always the maximum value, and the values at Point 3 are close to Point 1 and much higher than Point 2. At the same time, the values at Point 2 (the cracks are also dense) are higher than the others, and the strain gradually decreases with the decreasing cracks. This shows that although the strain value of the steel bar decreases along the mid-to-center direction, there is a wave-like alternating process. The reason is that during the bending process of the beam bottom, the concrete is cracked by the first failure of the tension, thereby causing stress redistribution on the surface of the steel bar, and is thus instantaneously reduced. But in the process of continuous stress, the overall tendency to increase (single point) and decrease (all longitudinal cracks extending from the middle to the ends) will not change.

In addition, comparing the three groups, the peak stress of $\mathrm{B}_{1}$ is $9.26 \mathrm{MPa}$, that of $\mathrm{B}_{2}$ is $17.19 \mathrm{MPa}$, and that of $\mathrm{B}_{3}$ is $18.37 \mathrm{MPa}$, which is $86 \%$ and $98 \%$ higher than the $\mathrm{B}_{1}$ beam, respectively. This indicates that as the concrete strength level increases and the diameter of the steel bars decreases, the bond peak stress increases. Figure 8 shows that the $\mathrm{B}_{1}$ beam has the most cracks at the bottom, while the $\mathrm{B}_{3}$ beam has only one main crack. This is because the bond strength is decreased with the increase of the steel bar diameter. And the concrete strength of the $\mathrm{B}_{1}$ beam is lower, so the concrete matrix will inevitably produce most cracks.

\subsubsection{Analysis of the Fitting Curves}

The segmentation fit is performed on the rising and falling sections of the $\mathrm{B}_{2}$ beam test curve.

Let

$$
x=\frac{\varepsilon}{\varepsilon_{0}}, y=\frac{\tau}{\tau_{0}}
$$

where $\varepsilon_{0}$ is the peak strain (10-6), and $\tau_{0}$ is the peak stress (MPa).

Ascending section curve:

$$
y=a_{0}+a_{1} x+a_{2} x^{2}+a_{6} x^{6}, x \leq 1
$$


Boundary conditions: when $x=0$, then $y=0$. When $x=1$, then $y=1$ and $\mathrm{d} y / \mathrm{d} x=$ 0 .

$$
\begin{aligned}
& \text { So } a_{0}=0, a_{1}+a_{2}+a_{6}=1, a_{1}+2 a_{2}+6 a_{6}=0 \text {, letting } a_{6}=\alpha \text { : } \\
& y=(2+4) x-(1+5 a) x^{2}+\alpha x^{6}, x \leq 1
\end{aligned}
$$

Descending section curve:

$$
y=\frac{x}{\beta(x-1)^{1.7}+x}
$$

Figure 9 shows the stress-strain curves of the strain gauges at different locations, and table 7 shows the corresponding fitting parameters and correlation coefficients.

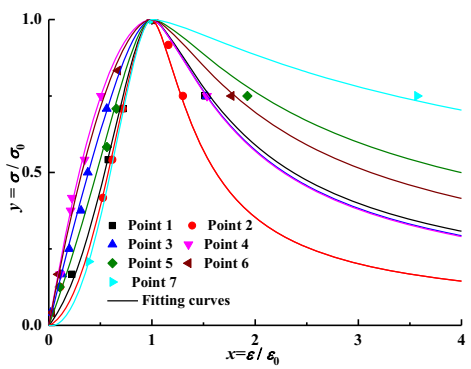

Figure 9. Fitting curves of $\mathrm{B}_{2}$.

Table 7. Fitting parameters $(\alpha, \beta)$ and correlation coefficients $\left(R^{2}\right)$.

\begin{tabular}{lllll}
\hline \multirow{2}{*}{ No. } & Ascending & \multicolumn{3}{l}{ Descending } \\
\cline { 2 - 5 } & $\alpha$ & $R^{2}$ & $\beta$ & $R^{2}$ \\
\hline 1 & -0.40 & 0.9069 & 1.39 & 0.9447 \\
2 & -0.47 & 0.9182 & 3.66 & 0.9335 \\
3 & -0.15 & 0.9443 & 1.49 & 0.9997 \\
4 & -0.006 & 0.9135 & 1.51 & 0.9449 \\
5 & -0.27 & 0.8988 & 0.62 & 0.9262 \\
6 & -0.05 & 0.9277 & 0.87 & 0.9493 \\
7 & -0.51 & 0.9625 & 0.26 & 0.9651 \\
\hline
\end{tabular}

It can be seen from the fitting parameters and correlation coefficient analysis that equation (6) $\sim$ equation (8) can correctly reflect the stress-strain relationship of different measuring points. This shows that the overall stiffness of the beam is consistent and uniform before reaching the ultimate state. After reaching the ultimate state, the bearing capacity is reduced and the stiffness is reduced due to the crack generated in the substrate. The stiffness damage is more serious near the mid-span position because of the hinge, and the stiffness is rapidly reduced. However, the stiffness change is less obvious away from the mid-span.

The fitting coefficient of the ascending section is averaged to obtain $\bar{\alpha}=-0.2$, which is substituted into equation (7b). It is found through calculation and analysis that the rising section of the curve is consistent with the rising section of the curve of the 
concrete tension curve. This shows that the bond properties of the concrete and steel bars mainly depend on the tensile properties of concrete.

It is known that the regression equation of the coefficient of the falling section of the tensile stress-strain curve of Guo and Zhang [42] can be represented as follows.

$$
\beta_{\mathrm{G}}=0.312 f_{\mathrm{t}}^{2}
$$

where $\beta_{\mathrm{G}}$ is the coefficient of the descending section of the concrete tensile model.

Ref. GB/T 50152-2012 [39] shows the relationship of $f_{\mathrm{t}} \sim f_{\mathrm{cu}}$.

$$
f_{\mathrm{t}}=0.395 f_{\mathrm{cu}}^{0.55}
$$

The tensile strength of concrete is $2.14 \mathrm{MPa}$, which is substituted into equation (9). It can get a coefficient of 1.4 , which is consistent with the average value of the test fitting coefficient. This indicates that the beam test is suitable for Guo's tensionbearing model.

It is found that the stress-strain curve equation obtained by this test is consistent with Guo's tensile stress-strain curve equation. This shows that the bond performance between the reinforcement and concrete depends entirely on the tensile properties of the concrete itself.

\subsubsection{Load-Deflection Curve Analysis}

The specimen $\mathrm{B}_{3}$ is taken for analysis to explore the conditions necessary to meet the horizontal tension of the steel bar at the bottom of the beam. For the simply supported beam structure, the bending moment values of each beam section under the bending load are not equal, and the section stiffness or curvature changes accordingly. As the load increases, the bending moment values at each section of the beam increase correspondingly, resulting in a change in the stiffness of each section (see equation 10).

$$
w=\iint\left(\frac{1}{R_{\mathrm{c}}}\right) \mathrm{d} x^{2}=\iint \frac{M(x)}{B_{x}} \mathrm{~d} x^{2}
$$

where $R_{\mathrm{c}}$ is the radius of curvature and $B_{x}$ is the section stiffness at section $x$.

The concrete in the purely curved section of the beam at the stage of the fullsection concrete is subjected to force (tension or compression) before the occurrence of the cracks. If the area of the steel bar in the pull zone is $A_{\mathrm{S}}$, the converted area is $n A_{\mathrm{S}}$, where $n=E_{\mathrm{S}} / E_{\mathrm{LC}}, E_{\mathrm{S}}=200 \mathrm{GPa}$ is the elastic modulus of the steel, and $E_{\mathrm{LC}}$ means the elastic modulus of the ALWC.

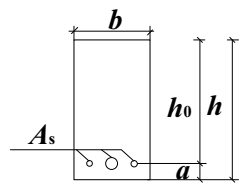

(a) Original section.

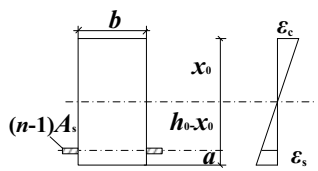

(b) Conversion section before cracking.

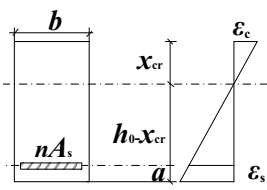

(c) Conversion section after cracking.

Figure 10. Sketch for conversion cross-section. 
In addition, it is necessary to add an additional area $(n-1) A_{\mathrm{S}}$ at the same height of the section to ensure that the stress on the converted area of the steel is equal to the concrete stress at the height of the corresponding section.

$$
\begin{aligned}
& A_{0}=b h+(n-1) A_{\mathrm{s}} \\
& \frac{1}{2} b x_{0}^{2}=\frac{1}{2} b\left(h-x_{0}\right)^{2}+(n-1) A_{\mathrm{S}}\left(h-x_{0}\right) \\
& x_{0}=\frac{\frac{1}{2} b h^{2}+(n-1) A_{\mathrm{S}} h_{0}}{b h+(n-1) A_{\mathrm{S}}}
\end{aligned}
$$

So,

$$
\begin{aligned}
& I_{0}=\frac{b}{3}\left[x_{0}^{3}+\left(h-x_{0}\right)^{3}\right]+(n-1) A_{\mathrm{S}}\left(h_{0}-x_{0}\right)^{2} \\
& B_{0}=E_{\mathrm{LC}} I_{0} \\
& w=\frac{F x}{48 E_{0}}\left(3 l^{2}-4 x^{2}\right), 0 \leq x \leq l / 2,
\end{aligned}
$$

It is assumed that the crack section is completely pulled out of the concrete in the tension zone after the crack occurs, and now only the steel bar bears the tensile force. The converted concrete area is placed at the same section height, the converted concrete section is obtained as shown in figure $10 \mathrm{c}$, and the height of the compression zone $x_{\mathrm{cr}}$ of the crack section is determined in the same way, where $\mu=A_{\mathrm{s}} /\left(b h_{0}\right)$. Figure 11 shows the load-deflection curves with different stiffness.

$$
\begin{aligned}
& \frac{1}{2} b x_{\mathrm{cr}}^{2}=n A_{\mathrm{S}}\left(h_{0}-x_{\mathrm{cr}}\right) \\
& x_{\mathrm{cr}}=\left(\sqrt{n^{2} \mu^{2}+2 n \mu}-n \mu\right) h_{0} \\
& I_{\mathrm{cr}}=\frac{1}{3} b x_{\mathrm{cr}}^{3}+n A_{\mathrm{S}}\left(h_{0}-x_{\mathrm{cr}}\right)^{2} \\
& B_{\mathrm{cr}}=E_{\mathrm{LC}} I_{\mathrm{cr}} \\
& w=\frac{F x}{48 E_{\mathrm{cr}}}\left(3 l^{2}-4 x^{2}\right), 0 \leq x \leq l / 2
\end{aligned}
$$




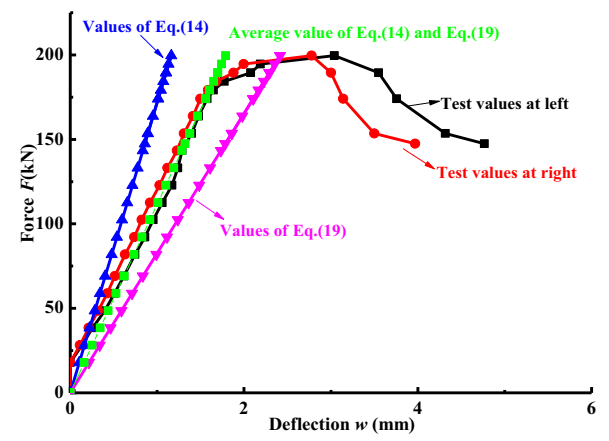

Figure 11. Load-deflection curves.

Figure 11 shows that the curve stiffness calculated according to the case where the concrete is not cracked is large, and the curve stiffness obtained by the tensile force of the steel bar in the tension zone is small according to the concrete cracking. Taking the average of the two cases, the curve obtained is basically consistent with the slope of the previous test curve, which means that the cracking of the concrete cannot be simply considered, and should be considered comprehensively according to the actual situation. In this paper, two test curves can be obtained before and after concrete cracking, and then the two test curves are averaged to obtain an approximate test curve, and remain basically consistent with the experimental values.

Table 8 summarizes the different dimensions of the beam specimens. Figure 12 shows the scatter plot for $\tau_{0}$ versus $S_{0}$. It shows that the bond strength increases with the increase of concrete strength and decreases with the increase of the diameter of the steel bar, while the $S_{0}$ is reduced with increasing strength and decreasing diameter. The $\tau_{0}$ obtained by different matrix materials and different beam test conditions is quite different.

The $S_{0}$ of ALWC is above $1 \mathrm{~mm}$, which is significantly higher than selfcompacting concrete (SCC) and NWC (not more than $1 \mathrm{~mm}$ ). For the beam test with the same compressive strength, the concentrated load of ALWC is higher than SCC and NWC, but the mid-span deflection is generally lower than others, which indicates that the bond performance of ALWC is indeed better than others. The $S_{0}$ of ALWC is significantly higher than others because of the lower elastic modulus of ALWC. Figures 5 and 12 show that the limit of $S_{0}$ for pull-out specimens is $2 \mathrm{~mm}$, and for beam specimens is $1 \mathrm{~mm}$, which means that the bond performance studied by the beam test is superior to the pull-out test.

Table 8. Parameters of bond-slip in this paper and the literature based on beam test.

\begin{tabular}{|c|c|c|c|c|c|c|c|c|c|c|c|}
\hline Type & $\begin{array}{l}f_{\mathrm{cu}} \\
\text { (MP } \\
\text { a) }\end{array}$ & $\begin{array}{l}b \times \\
h \times \\
l\end{array}$ & $\begin{array}{l}l_{0} / \\
h\end{array}$ & $\begin{array}{l}b / \\
h\end{array}$ & $w_{0}$ & $S_{0, \mathrm{~L}}$ & $S_{0, \mathrm{R}}$ & $\begin{array}{l}F_{0} \\
(\mathrm{kN} \\
)\end{array}$ & $\begin{array}{l}\tau_{0} \\
\text { (MP } \\
\text { a) }\end{array}$ & $\begin{array}{l}d \\
(\mathrm{~mm} \\
)\end{array}$ & $\begin{array}{l}l_{\mathrm{a}} \\
(\mathrm{mm} \\
)\end{array}$ \\
\hline ALWC-B 1 & 31 & $\begin{array}{l}150 \\
\times\end{array}$ & & & 3.67 & $\begin{array}{l}2.9 \\
5\end{array}$ & - & 92 & 4.81 & 25 & $\begin{array}{l}2 \\
\times \\
250\end{array}$ \\
\hline ALWC-B ${ }_{2}$ & 36 & $\begin{array}{l}240 \\
\times \\
127\end{array}$ & $\begin{array}{l}4.1 \\
7\end{array}$ & $\begin{array}{l}0.6 \\
3\end{array}$ & 5.52 & $\begin{array}{l}1.1 \\
3\end{array}$ & - & 112 & 8.55 & 20 & $\begin{array}{l}2 \\
\times \\
200\end{array}$ \\
\hline ALWC-B 3 & 38 & 0 & & & 2.09 & $\begin{array}{l}0.9 \\
6\end{array}$ & - & 200 & $\begin{array}{l}22.3 \\
8\end{array}$ & 16 & $\begin{array}{l}2 \\
\times \\
160\end{array}$ \\
\hline
\end{tabular}




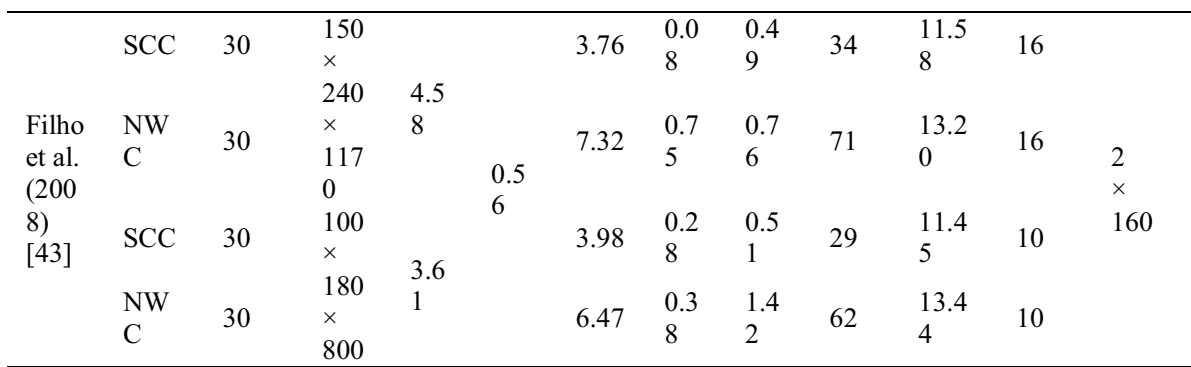

Note: $S_{0, \mathrm{~L}}$ is the slip at the left, $S_{0, \mathrm{R}}$ means the slip at the right.

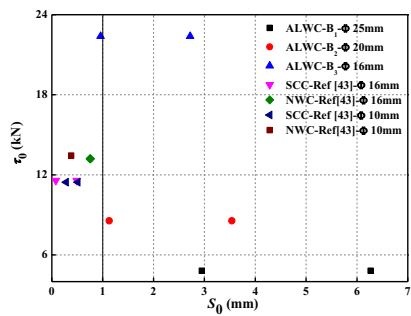

Figure 12. Scatter plot for $\tau_{0}$ versus $S_{0}$ of beam tests.

\section{Comparative Analysis and Discussion of the Two Test Methods}

Figure 13 shows the $\tau_{0}-S_{0}$ studied in this paper and other literature and indicates that the peak bond stress of the beam specimens and the pull-out specimens remains within the same variation range, and that the peak slip of the beam specimens is generally lower than the pull-out specimens. Comparing the two types of test methods with the same compressive strength of $30 \mathrm{MPa}$ and the same bar size of $20 \mathrm{~mm}$ as the comparison object, the ultimate load $(216 \mathrm{kN})$ of the beam test specimen is 3.66 times that $(59 \mathrm{kN})$ of the pull-out test, and the peak slip of the pull-out specimen is 4.80 times that of the beam specimen. This shows that under the same conditions, the pull-out test is more sensitive to the reaction of the bond performance; the preparation is simple, the test is convenient, and it is suitable for the sampling test in the laboratory; and the beam test can better reflect the relationship between the steel and the concrete. The bond performance is suitable for structural tests and is closer to engineering practice. However, due to the effect of stirrups and large cross-sectional dimensions, it is impossible to reflect the significant form of damage as the pull-out test can.

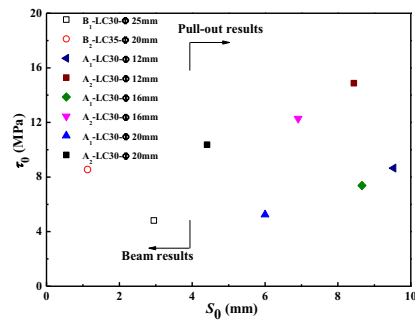

Figure 13. Bond strength versus slip distribution for beam specimens and pull-out specimens. 


\section{Conclusions}

This study was based on the analysis of the bond properties of lightweight aggregate concrete and several different sizes of steel bars; two types of tests such as pull-out tests and beam tests, were conducted. This study presents corresponding physicalmechanical analysis models and analyzes the influencing factors that affect the bond performance, reaching the following conclusions:

(1) A physical-mechanical analysis model was established and a transform relationship could convert the load-slip curves directly obtained by the sensor of the test machine to the $\tau$ - $S$ curves that directly reflect the bond stress of the anchor section. All the types of damage with complete ascending and descending segments are pull-out failure, and only the ascending segment and the shorter anchored specimens generally undergo splitting failure.

(2) The beam test cannot accurately obtain the deflection curve due to the change of the beam section stiffness caused by the generation of cracks in the tension zone during the loading process. This paper obtained a deflection curve according to the calculation of the section moment of inertia by the converted section before and after the crack in the tension zone, and the sectional dimensions are given in order to keep the bottom bars in tension.

(3) The bond stress of the pull-out test specimens and the beam test specimens are the same or similar under the conditions of the same mix ratio, and both decrease with the increase of the diameter of the steel bar, although the ultimate load of the former is about 3.66 times that of the latter. For the peak slip, the test result in this paper is larger than in the relevant literature. The pull-out specimens are no more than $10 \mathrm{~mm}$, whereas in the other literature they are less than $2 \mathrm{~mm}$, while the beam specimens are no more than $3 \mathrm{~mm}$ where the others are generally around $1 \mathrm{~mm}$.

This study shows the results of the pull-out tests and beam tests through theoretical derivation and experimental verification, and eliminates the influence of the free section of the steel bar in the pull-out test and the deflection and angle of the beam test. The results show that the theory is consistent with the experimental results, and the beam test has multiple differences compared with the pull-out test due to the influence of the section size and the stirrup. It is closer to the engineering practice, but it cannot reflect the remarkable features of the pull-out damage and splitting damage as the pullout test can. Therefore, the pull-out test is used to study the bond properties of steel and concrete and the beam test is used to verify the engineering bond performance.

In addition, in order to improve the ductility of the structure and avoid the occurrence of splitting damage under the same conditions, it is better to use smaller diameter steel bars to improve the energy consumption effect by extracting and destroying as much as possible, and improving the seismic performance of the structure.

Since the bond-slip performance is related to the friction coefficient of steel-concrete, there are still few similar tests, especially the friction coefficient measurement test of lightweight aggregate concrete-reinforced steel. In addition, the bond-slip properties of steel bars and different lightweight aggregate concrete in solid reinforced concrete beams under static and dynamic loads, as well as bond-slip properties under different complex conditions, including durability, water and high or low temperature conditions, are experimental research items that need to be considered in the next step, so as to complement and improve the relevant finite element analysis model. 


\section{Acknowledgements}

This work was financially supported by the National Natural Science Foundation of China $(41172317 ; 51774112 ; 51474188)$, the Doctoral Fund of Henan Polytechnic University (B2015-67), and Taihang Scholars Program. This paper was polished by Proof-Reading-Service.com Ltd.

\section{References}

[1] Mo KH, Alengaram UJ, Jumaat MZ. Bond properties of lightweight concrete - a review. Construction and Building Materials. 2016 Jun;112: 478-496.

[2] Sarhan MM, Hadi MNS, Teh LH. Bond behavior of steel plate reinforced concrete beams. Construction and Building Materials. 2018 Nov;189: 751-756.

[3] Desnerck P, Lees JM, Morley CT. Bond behaviour of reinforcing bars in cracked concrete. Construction and Building Materials. 2015 Jun;94: 126-136.

[4] Rolland A, Quiertant M, Khadour A, Chataigner S. Experimental investigations on the bond behavior between concrete and FRP reinforcing bars. Construction and Building Materials. 2018 Jun;173:136148.

[5] Patel VJ, Van BC, Henry RS, Clifton GC. Effect of reinforcing steel bond on the cracking behaviour of lightly reinforced concrete members. Construction and Building Materials. 2015 Jun; 96:238-247.

[6] Carvalho PE, Miranda PM, Fernandes DSG, Alves GV. Comparison of test methodologies to evaluate steel-concrete bond strength of thin reinforcing bar. Construction and Building Materials. 2018 Sep;183:243-252.

[7] Bae BI, Choi HK, Choi CS. Bond stress between conventional reinforcement and steel fibre reinforced reactive powder concrete. Construction and Building Materials. 2016 Jun;112:825-835.

[8] Zhao J, Cai G, Yang J. Bond-slip behavior and embedment length of reinforcement in high volume fly ash concrete. Materials and Structures. 2016 Jun;49(6):2065-2082.

[9] Wang L, Yi J, Xia H, Fan L. Experimental study of a pull-out test of corroded steel and concrete using the acoustic emission monitoring method. Construction and Building Materials. 2016 Jun;122:163-170.

[10] Shen D, Shi X, Zhang H, Duan X, Jiang G. Experimental study of early-age bond behavior between high strength concrete and steel bars using a pull-out test. Construction and Building Materials. 2016 Jun;113:653-663.

[11] Arel HŞ, Yazici Ş. Concrete-reinforcement bond in different concrete classes. Construction and Building Materials. 2012 Nov;36:78-83.

[12] Rilem TC. RC 6 Bond test for reinforcement steel. 2. Pull-out test, 1983. New York: E \& FN SPON; 1994; p. 218-220.

[13] Bogas JA, Gomes MG, Real S. Bond of steel reinforcement in structural expanded clay lightweight aggregate concrete: The influence of failure mechanism and concrete composition. Construction and Building Materials. 2014 Jun;65:350-359.

[14] Lee J, Sheesley E, Jing Y, Xi Y, Willam K. The effect of heating and cooling on the bond strength between concrete and steel reinforcement bars with and without epoxy coating. Construction and Building Materials. 2018 Jul;177:230-236.

[15] Darwin D, Matamoros AB. Bond and Development of Reinforcing Bars in Tension (ACI 408R-03) Farmington Hills: American Concrete Institute; 2003. 49p.

[16] GB 50010-2010. Code for design of concrete structures, China, 2010 (in Chinese).

[17] Mousa MI. Effect of bond loss of tension reinforcement on the flexural behaviour of reinforced concrete beams. HBRC Journal. 2016 Dec;12(3):235-241.

[18] Prince MJR, Gaurav G. Splice strength of deformed steel bars embedded in recycled aggregate concrete. Structure Journal. 2017 May;10:130-138.

[19] Dehestani M, Asadi A, Mousavi SS. On discrete element method for rebar-concrete interaction. Construction and Building Materials. 2017 Jun;151:220-227.

[20] Mazaheripour H, Barros JAO, Sena-Cruz JM, Pepe M, Martinelli E. Experimental study on bond performance of GFRP bars in self-compacting steel fiber reinforced concrete. Composite Structure. 2013 Jan;95:202-212.

[21] Chikh N, Merdas A, Laraba A, Benzaid R. Study of the bond behavior of concrete beam strengthened with NSM - CFRP. Lecture Notes in Engineering and Computer Science. 2013 Jul;2206(1):430-437. 
[22] Lee SW, Kang SB, Tan KH, Yang EH. Experimental and analytical investigation on bond-slip behaviour of deformed bars embedded in engineered cementitious composites. Construction and Building Materials. 2016 Jun; 127:494-503.

[23] Ma YF, Guo ZZ, Wang L, Zhang JR. Experimental investigation of corrosion effect on bond behavior between reinforcing bar and concrete. Construction and Building Materials. 2017 Jun;152:240-249.

[24] El-Nemr A, Ahmed EA, El-Safty A, Benmokrane B. Evaluation of the flexural strength and serviceability of concrete beams reinforced with different types of GFRP bars. Engineering Structures. 2018 Oct;173:606-619.

[25] Pokorný P, Tej P, Kouřil M. Evaluation of the impact of corrosion of hot-dip galvanized reinforcement on bond strength with concrete - A review. Construction and Building Materials. 2017 Jun;132:271-289.

[26] Zemour N, Asadian A, Ahmed EA, Khayat KH. Experimental study on the bond behavior of GFRP bars in normal and self-consolidating concrete. Construction and Building Materials. 2018 Nov; 189:869-881.

[27] Al-Shannag MJ, Charif A. Bond behavior of steel bars embedded in concretes made with natural lightweight aggregates. Journal of King Saud University - Engineering Sciences. 2017 Jun;29(4):365372 .

[28] Zhuang YZ, Chen CY, Ji T. Effect of shale ceramsite type on the tensile creep of lightweight aggregate concrete. Construction and Building Materials. 2013 Sep;46:13-18.

[29] Maree AH, Riad KH. Analytical and experimental investigation for bond behaviour of newly developed polystyrene foam particles' lightweight concrete. Engineering Structures 2014 Jan;58:1-11.

[30] Mattock AH, Li WK, Wang TC. Shear transfer in lightweight reinforced concrete. PCI Journal. 1976 Jan;21(1): 20-39.

[31] JGJ 51-2002. Technical specification for lightweight aggregate concrete, China, 2002 (in Chinese).

[32] Taylor MA, Jain AK, Ramey MR. Path dependent biaxial compressive testing of an all-lightweight aggregate concrete. ACI Journal 1972 Jun;69(12):758-764.

[33] GB/T 17431.1-2010. Lightweight aggregates and their test methods - Part 1: Lightweight aggregates, China, 2010 (in Chinese).

[34] GB 175-2007. Common Portland cement, China, 2007 (in Chinese).

[35] GB/T 1596-2005. Fly ash used for cement and concrete, China, 2005 (in Chinese).

[36] GB 8076-2008. Concrete admixtures, China, 2008 (in Chinese).

[37] JGJ 63-2006. Standard of water for concrete, China, 2006 (in Chinese).

[38] GB 1499.2-2007. Steel for reinforcement of concrete - Part 2: Hot-rolled ribbed bars, China, 2007 (in Chinese).

[39] GB/T 50152-2012. Standard for test method of concrete structures, China, 2012 (in Chinese).

[40] Wu X, Wu Z, Zheng J, Zhang X. Bond behavior of deformed bars in self-compacting lightweight concrete subjected to lateral pressure. Magazine of Concrete Research. 2013 Dec;65(23):1396-1410.

[41] Zhang D, Yang W. Experimental research on bond behaviors between shale ceramsite lightweight aggregate concrete and bars through pullout tests. Journal of Materials in Civil Engineering. 2014 Jun;27(9):06014030.

[42] Guo ZH, Zhang XQ. Experimental investigation of complete stress-deformation curves of concrete. Journal of Building Structures. 1988 Aug;04:45-53. (in Chinese).

[43] Filho FMDA, Debs MKE, Debs ALHC. Bond-slip behavior of self-compacting concrete and vibrated concrete using pull-out and beam tests. Construction and Building Materials. 2008 Jul;41(6):1073-1089. 